\title{
The Influence of Self-Media on the Mental Health of Vocational School Students and its Educational Countermeasures
}

\author{
Xuan Luo \\ Beijing Vocational College of Agriculture, Beijing 100012, China
}

Keywords: self-media; vocational school students' mental health education; influence and countermeasures

\begin{abstract}
The development of the network has made the whole world narrow into a "global village", making the exchanges and contacts between countries more closely, at the same time, there is a rapid development of the self-media as the basis of Internet. The self-media promotes the development of national culture, but also has brought severe challenges to national culture. The media is a double-edged sword, which can bring a double impact on mental health of vocational school students. To this end, this paper put forward to improve the relevant network regulations, to create a healthy and orderly network environment. The media is a good way to strengthen the propaganda and other recommendations for vocational school students' mental health education.
\end{abstract}

\section{Introduction}

With the development of the Internet, self-media as a fashion culture, is a unique expression of the culture to the latest human science and technology achievements as the carrier of the Internet, relying on modern developed and fast information transmission system, the use of certain tools and symbols to convey ideas, culture and customs, to express their views, to vent their emotions, to build a new way of thinking and cultural expression, as the present generation of a unique and beautiful cultural landscape. Since the rapid development of the media has brought great influence on people's life, especially the behavior pattern, value orientation, political attitude, psychological development, morality and so on. Vocational school students have a certain degree of vibration, which affects the psychology of part of vocational school students health. This brings the opportunity and the serious challenge to the mental health education of the vocational school students. Therefore, the mental health education of vocational school students has become a very important new topic in modern colleges and universities.

\section{The influence of self-media on mental health education of vocational school students}

\section{The meaning of vocational school students' mental health education under the self-media environment}

Since the self-media is a subculture, it is based on computer and communication technology as a new culture. As for the self-media, its information is large, and its content are rich. There are new ideas and they change fast. Actually, it is a good way to contact vocational school students to provide a new understanding and grasp the new environment of things, to affect the students of the world view, outlook on life, values and to affect the mental health of vocational school students, which will give the healthy growth of vocational school students to bring some adverse effects. According to China Internet Network Information Center (CNNIC) released the survey data, as of the end of June 2008, the number of Chinese Internet users reached 253 million, of which 18 to 24 years old accounted for $42.8 \%$, which is the age of vocational school students. It can be seen that since the self-media more and more favored by vocational school students, at the same time it also brings more and more mental health problems for the vocational school students. Therefore, for this 
situation, the network under the conditions of vocational school students mental health education refers to the education through the computer Internet education platform, a planned and organized to help students understand the mental health of knowledge theory, to master the way to achieve mental health and methods, to learn to adjust and correct the unhealthy psychology, so as to promote vocational school students' knowledge, love, meaning, and other aspects of development to a better state of all the practical activities carried out in order to better adapt to society and promote social development. The positive impact of media on the mental health education of vocational school students.

\section{The universality and timeliness of the media is conducive to the timeliness of mental health education for vocational school students}

Since the restoration of college entrance examination, the number of vocational school students in China have got more and more mental health problems. So from the beginning of the 20th century, the following vocational school students' mental health education should be emphasized. In 1990, the Ministry of Education set up a national professional counseling committee of vocational school students to strengthen the national college mental health education work of macro guidance, and in 2001 and 2002, respectively, promulgated the "on strengthening the general vocational school students' mental health education work "and" the implementation of the outline of the mental health education of vocational school students in vocational colleges (Trial) ". At the same time, some colleges and universities have also set up a vocational school students' mental health education leading group.

\section{The equality of the media for the vocational school students can enhance the acceptability of mental health education}

Educator IELTSBUS in the What is Education said, "educators cannot ignore the reality of the students and mental state, and that they are superior to students, so students cannot be treated equally with the students, and teachers cannot open their own heart to the students. "It is understood that many school students do not want to go to the school's psychological counseling room to conduct psychological counseling, the reason is that they feel and teachers in the process of communication, feeling no self-esteem, no subjectivity, as if in accepting the teacher's preaching, the teacher does not pay attention to the psychological characteristics of the students, so that students are in a passive state of acceptance. This way not only did not solve the psychological problems of students, but to students rebellious, such education must be a failure. However, the self-media can shorten the distance, from passive education to self-conscious education. First of all, the modern vocational school students to pursue the inherent equality, advocating the refraction of the media from the democratic, free, equal values, hoping to eliminate the reality of the Internet inequality. So that they are equal to the identity of Internet users and education to communicate the main body, can be relatively free to talk about life, talk about ideals, thus forming a positive interaction. Second, the virtual features of the network can eliminate the ideological concerns of vocational school students. Third, since the media in a variety of forms, rich content, which can seize the psychological characteristics of vocational school students, it is easy for vocational school students to accept. At this time, the educators no longer have to face the face of the students to preach, to persuade, but to guide the direction of the students. This way of education is more humane and affinity, but also can achieve the best results of education.

\section{The new method of mental health for college students}

The National Conference on Media Construction and Management, held on June 3, 2007, made us realize that the rapid development of technology requires that we must stand at the forefront of world science and technology and cultural development, rethink ideas and management from media. Therefore, the development of Chinese characteristics from the media, to strengthen and improve the vocational school students' mental health education, is related to the Chinese vocational school students and thus related to China's future fate of the strategic choice. 


\section{To improve the relevant network regulations, to create a healthy and orderly network environment}

Since the media is open, but the media cannot violate the relevant laws and regulations, and social development and coordination, while the government should introduce relevant laws to regulate the media from the environment. Although China has developed a "computer information security protection regulations" and a series of laws and regulations, effectively maintaining the information in the network environment in order to spread. Because the law is not perfect, and the operation is complex, some lawless elements to provide a chance to take, and thus spawned a network of crime, from the following four aspects to purify the media environment. First, to increase the intensity of legislation, so that the media can be law, according to law, law enforcement must be strict, illegal research. Second, by improving the relevant information technology means to strengthen the negative thoughts on the Internet and backward, wrong thinking to take timely precautions, to improve or remove bad information. At the same time to strengthen exchanges and cooperation with international organizations, the development of relevant laws and regulations to control the spread of bad information, so as to purify the media environment. Third, the relevant departments of society to do words and deeds consistent, co-ordination, to prevent illegal websites and Internet cafes, to increase the illegal websites and illegal Internet cafes punished. Fourth, the creation of a civilized website, in particular, to strengthen the construction of the campus network, to create a healthy school students, healthy and orderly network environment.

\section{Through the media, to strengthen the propaganda of vocational school students' mental health education}

Now there are a lot of vocational school students who use Internet very much, therefore, with the development of the media, vocational school students in modern society should understand the information, which provides a favorable way to promote the mental health education of vocational school students. Four ways can play the effect of publicity, which can strengthen the vocational school students' mental health education. First, the government, the relevant educational institutions and colleges should pay attention to, through the media from the platform to carry out nationwide vocational school students' mental health education activities, and the establishment of mental health education and mental health education month, so that mental health education into vocational school students mind. Second, colleges and universities in the promotion of vocational school students in the process of mental health education can learn from the vocational school students ideological and political education publicity, through the campus network to vocational school students can voluntarily to detect, consult their mental health, and thus accepting a good psychological health education, so that their psychology can be timely adjustment. Third, from the media environment also need to strengthen the vocational school students' mental health education, to vocational school students to provide more mental health knowledge, so that they contact the network in the process of mental health education to achieve the purpose. Fourth, teaching materials of network, network teaching should have a clear penetration of mental health education knowledge, training vocational school students' mental health education consciousness.

\section{Conclusion}

In short, to make good use of this important channel from the media, the vocational school students mental health education work plan, which is good to make vocational school students self-educate, so that they will develop a sound personality and good psychological quality.

\section{References}

[1] Wang Shiming. Technology, Self-media and Cultural changes [J]. Information magazine, 2004 (4).

[2] Chen Weidong, Han Xuefeng. Self-media Interpretation [J]. Modern distance education, 2006 
(6).

[3] Huang Wenling. The Value of the Self-media and Its Development Path [J]. Journal of Huazhong Agricultural University (Social Science Edition), 2005 (2).

[4] Yang Jianyu. The Impact of Media on College Students' Ideological and Political Work and its Countermeasures [J]. Journal of Yunnan Higher Education Research, 2000,18 (2).

[5] Wei Haitang. "Network Society" on the Ideological and Political Quality of Vocational Students Negative Impact and Educational Countermeasures [J]. Higher Education, 2000 (7).

[6] Wei Xinjun. Urgent Need to Strengthen the Contemporary Vocational School Students Mental Health Education [J]. Exploration, 2008 (8).

[7] [Germany] Ieltsbuses. What is Education [M]. Zou Jin, translation. Beijing: life, reading and new knowledge of Sanlian bookstore, 1991. 